\title{
DEBATENDO OS COMITÊS DE ÉTICA: CONTROLE BUROCRÁTICO OU LAISSEZ-FAIRE?
}

Eduardo Augusto Tomanik ${ }^{*}$

Quatro anos atrás, preocupado e incomodado com os rumos que vinham tomando as atividades exercidas por alguns comitês de ética, publiquei uma proposta de discussão sobre o tema, nessa mesma Revista (Tomanik, 2008). Graças a esta publicação, conheci Ronie Silveira e Simone Maria Huning, que me convidaram a participar, com eles, de uma Sessão Coordenada, durante o XV Encontro Nacional da Associação Brasileira de Psicologia Social (ABRAPSO), na qual pudemos expor nossas análises e propostas sobre aquele tema. As apresentações deram origem a um debate bastante acalorado e rico.

Encerrada formalmente a Sessão, Silveira e eu continuamos nossa conversa, em outro local. Desde então, temos trocado mensagens e desenvolvemos o que considero uma ótima relação de amizade. Tornamo-nos amigos não apesar das nossas divergências, mas justamente por elas.

Foi neste clima que recebi o texto intitulado Gambiarra Ética, juntamente com o convite feito por seu autor, para debatê-lo. Com a mesma disposição afetiva pretendo elaborar e apresentar minha resposta, e é por ela que me permito a liberdade de chamar seu autor pelo primeiro nome, fugindo da formalidade usual nos textos científicos.

Admiro os conhecimentos, a habilidade de raciocínio e a disposição de Silveira em utilizar estes atributos na busca do que considera correto. Concordo com muito do que ele pensa e, diante do que continuo vendo acontecer com os comitês de ética, confesso que às vezes tenho sentido vontade de passar a adotar a sua proposição; no entanto, considero que as reflexões nas quais ele baseia sua proposta final evidenciam duas tendências de raciocínio com as quais não consigo concordar, e é por este ponto que vou iniciar meus comentários.

\section{ALGUMAS DISCORDÂNCIAS BÁSICAS}

A primeira daquelas tendências envolve 0 que me parece um determinismo histórico, que estaria presente, de forma aparentemente disseminada em toda e qualquer instituição social. Silveira (2013) afirma, por exemplo, que

\footnotetext{
não podemos simplesmente agregar de fora funções que são incompatíveis com a dinâmica preexistente de uma entidade, qualquer que seja ela - sob pena de procedermos de maneira errática e sem nenhuma consideração pela maneira como o mundo opera (p. 172).
}

Em outras frases, refere-se a uma "(...) lógica imanente que a instituição "comitê de ética em pesquisa de uma universidade brasileira' possui, seja qual for sua manifestação particular concreta" (p. 172, destaques meus), e destaca: "por uma questão de organicidade básica do mundo, indivíduos bem-intencionados não podem mudar a lógica de funcionamento que definem as instituições" (p. 173).

Assim, segundo ele, instituições sociais, uma vez criadas, carregam em si destinações (finalidades nem sempre explícitas, mas imutáveis) e regras de funcionamento associadas àquelas destinações que não podem mais ser alteradas.

A segunda tendência de raciocínio presente no texto de Silveira (2013) pode ser considerada, a meu ver, como um forma de dualismo que se aproxima muito de um maniqueísmo, ou seja, de uma tentativa de distinção rígida e impermeável entre o certo e o

Doutor em Psicologia Social pela Pontifícia Universidade Católica de São Paulo. Professor Voluntário no Programa de Pós-

Graduação em Psicologia (Mestrado) na Universidade Estadual de Maringá. 
errado, o bem e o mal, ou, no caso, entre o que seria e o que não seria ético.

Esta tendência transparece claramente nas afirmações de que "um avaliador consciencioso será autoritário, porque terá que dizer o que é ético e o que não é, o que pode ser feito e o que não pode" (p. 175).

Para chegar a uma decisão como esta, segundo Silveira (2013), os avaliadores precisariam eleger previamente um ou alguns critérios, claros e definidos, que lhes permitissem determinar (unilateral e isoladamente) o que é e o que não é ético. A definição desses critérios, além de indispensável para a atuação dos comitês, serviria também para diferenciar qualitativamente seus membros e seus demais colegas, igualmente cientistas, mas não participantes de um comitê: "um comitê de ética só pode agir incorporando esses valores especiais que o colocam acima do status quo ético dos pesquisadores em geral" (Silveira, 2013, p. 173).

Ainda de acordo com a linha de pensamento adotada e exposta por ele, a existência desta superioridade ética é indispensável: "o comitê opera como um intermediário entre valores superiores (que possui) e valores inferiores (que existem). Ele poderá transmitir de maneira mais ou menos incisiva e cuidadosa essa superioridade, mas não poderá abdicar dela" (Silveira, 2013, p. 174).

Em meu texto anterior (Tomanik, 2008) apresentei a proposição de que os comitês de ética deveriam constituir-se, essencialmente, em espaços de reflexão. Concordo com Silveira em que isto Ihes possibilitaria exercer uma possível função pedagógica; mas para ele esta possível atuação pedagógica estaria igualmente condicionada àquela diferença qualitativa necessariamente existente entre membros e não membros dos comitês: "claro que um comitê pode realizar atividades pedagógicas, mas não pode negar sua essência superior. Sua vida depende da diferença entre ilustrados e não ilustrados eticamente, da distinção entre o que é certo e o que é errado" (p. 174). Ainda segundo Silveira (2013), “(..) só exerce uma função pedagógica quem tem a algo a dizer que é diferente e melhor do que o que os demais já sabem" (p. 173).

Ao longo de seu texto, estas duas tendências de pensamento acabam por combinar-se e interdeterminar-se. Assim, para Silveira (2013), da mesma forma que "(...) os comitês não podem negar sua natureza e os repiques de autoritarismo explícito serão uma ocorrência comum no seu funcionamento" ( $p$. 175), também "(...) não poderão jamais abandonar a pedagogia da diferença e da superioridade que faz parte de sua estrutura de funcionamento. Eles não podem saltar sobre a sua dinâmica interna e sobre os seus próprios princípios estruturais" (p. 174).

Em quê não concordo com estas linhas de raciocínio?

Em primeiro lugar, não consigo aceitar a concepção de que entidades criadas socialmente, mesmo que institucionalizadas, sejam imutáveis ou dotadas, desde sua origem e em função dela, de uma lógica intrínseca perene e inescapável. Se aquela concepção fosse correta a sociedade não passaria por transformações, uma vez que toda ela é composta por instituições.

Instituições são produtos sociais. Foram elaboradas, implantadas e instituídas por pessoas para atender aos interesses destas. Elas são mantidas, igualmente, por pessoas, mas possivelmente por outras, que não necessariamente enfrentam as mesmas contradições ou mantêm exatamente os mesmos interesses que suas criadoras originais. Ora, se pessoas, interesses, desafios, condições e momentos são diferenciados, por que as instituições, que só podem existir a partir das ações e decisões das pessoas, permaneceriam imutáveis?

Tenho a impressão de que a História mostra claramente as mudanças das instituições. Aliás, em última análise, se as instituições não sofressem alterações, talvez não pudéssemos sequer falar em História, ao menos como a concebemos hoje.

Instituições sociais, embora sejam instituições, permanecem sociais, e por isto podem ser e são transformadas. Ao menos assim prefiro acreditar.

Também não concordo com aquelas concepções dualistas que meu amigo e parceiro de debates utiliza como base para suas propostas. Antes de tudo, porque não concebo as reflexões éticas como a) um julgamento ou um confronto binário entre um certo e um errado, b) baseados em critérios ou em valores necessariamente superiores e, portanto, inquestionáveis e c) executados por um grupo do qual o sujeito da ação (pretendida ou executada) não faz parte. 
Prefiro considerar as decisões éticas como processos de reflexões que, partindo de princípios amplos e gerais, coletivamente desenvolvidos e compartilhados, buscam decidir sobre a pertinência da aplicação total ou parcial (e, eventualmente, da não aplicação) de um ou mais daqueles princípios a casos concretos e específicos. A elaboração destas reflexões deve levar em conta, necessariamente, tanto 0 contexto de ocorrência quanto os interesses e possibilidades dos participantes do caso. Deve, ainda, resultar em um estado de convicção interna do sujeito ou dos sujeitos, executores ou participantes das ações pretendidas ou deliberadas.

Assim, as deliberações éticas não devem constituir um julgamento, mas 0 desenvolvimento de uma reflexão. Isto implica que não devem nem podem constituir-se na mera aplicação automática e repetitiva de regras fixas, imutáveis e provenientes de quaisquer instâncias alheias aos sujeitos que deliberam. Assim não há por que ou como pensarmos em valores superiores, quaisquer que sejam eles. Os princípios norteadores das reflexões devem ser pactuados e estão igualmente sujeitos a questionamentos e mudanças. Por último, se as deliberações éticas envolvem necessariamente a adesão e a concordância dos responsáveis pela execução das ações, não podem ser realizadas sem a participação destes.

Prefiro, portanto, adotar a concepção do que Abib (2008) denomina de uma ética contextualista, oposta à "(...) teoria de que a moral deve valer-se de princípios abstratos e gerais, aplicáveis a qualquer caso" e que

(...) defende a compreensão da questão
ética como o estudo de situações. Com
a defesa de que não e possível aplicar
automaticamente regras morais
previamente estabelecidas para julgar,
por exemplo, casos de aborto e
eutanásia, uma ética contextualista
argumenta que a avaliação de uma
questão ética particular deve ser feita da
perspectiva da história e da situação dos
atores morais envolvidos. (p. 421,
destaque no original)

Tampouco compartilho das concepções que Silveira (2013) delineia sobre a pedagogia, mas isto é um ponto para outro debate.

De qualquer forma, é claro que, partindo de princípios tão opostos, não poderíamos, ele e eu, chegar a conclusões semelhantes.

\section{OUTRAS DISCORDÂNCIAS}

Em outros pontos de seu texto Silveira (2013) afirma que "(...) os comitês de ética são figuras do autoritarismo político do Estado brasileiro tentando gerenciar a vida ética de seus cidadãos" (p. 174) e que sua criação constituiu um "(...) ato político ditatorial" (p. 175). Somando estas afirmações ao conjunto de suas reflexões, ele apresenta a proposta de que "(...) as universidades brasileiras se tornem responsáveis e adultas; que fechem seus comitês de ética e transfiram esse grau de responsabilidade para seus pesquisadores" (p. 175).

Em defesa de sua proposta, Silveira (2013) afirma, referindo-se aos cientistas:

A grande maioria sabe o que é ético. A minoria que não quer saber, deverá sentir o peso da responsabilidade dos demais. Quem publica algo de um pesquisador sem ética? Quem é coautor com um pesquisador sem ética? Quem oculta uma pesquisa realizada sem ética? Quem faz vista grossa para os deslizes éticos dos colegas? Só os irresponsáveis agem assim. (p. 175)

Confesso que não conheço em detalhes o processo que resultou na criação dos comitês de Ética em Pesquisas com Seres Humanos no Brasil. Tenho a impressão, pelo resultado final, de que as discussões que antecederam a publicação da Resolução CNS 196/96 ficaram restritas aos pesquisadores das ciências biomédicas. Também acho questionável o fato de que o Conselho Nacional de Saúde legisle ou pretenda legislar sobre todas as pesquisas envolvendo seres humanos no país, sejam estas relacionadas ou não à área da saúde.

Por outro lado, não posso deixar de considerar que a criação dos comitês surgiu como resultado de uma intensa preocupação mundial em relação aos caminhos (ou descaminhos) que boa parte da produção científica havia tomado ou estava trilhando. Não vejo necessidade de citar exemplos, mas, infelizmente, todas as quatro perguntas que Silveira (2013) lança e que citei acima poderiam gerar uma série de respostas, e todas desagradáveis.

Cientistas não são melhores nem piores que os demais seres humanos. Sempre haverá ou, ao menos, sempre houve, nos meios acadêmicos e fora deles, aqueles que se movem por interesses absolutamente pessoais ou de 
grupos poderosos e que consideram que os outros (alguns ou quase todos) são, como disse aquela nossa pouco saudosa ministra, "um detalhe".

Aceitar a proposta de Silveira (2013), a meu ver, implica em ignorar a História, e o preço disto pode ser alto.

\section{MUITO ALÉM DA "REFORMA TOMANIK"}

Confesso que fiquei lisonjeado ao ver meu nome associado a uma proposta de mudança de alguma coisa; mas não posso aceitar tal homenagem (ainda que ela seja feita apenas para ser desconstruída). Muitos outros colegas têm igualmente exposto suas preocupações sobre o papel dos comitês de ética em pesquisa com seres humanos no Brasil, a maioria deles com base em reflexões teóricas melhores e mais profundas que as minhas e com maior experiência e com mais competência que eu.

Estas preocupações, encampadas por instituições representativas de grupos de cientistas, têm gerado ações coletivas e organizadas, debates e documentos que evidenciam toda a complexidade do tema e ressaltam a existência de inadequações na Resolução CNS 196/96 e no sistema que foi gerado a partir dela.

Apenas como exemplos, posso citar uma série de iniciativas lideradas pela Associação Nacional de Pesquisa e Pós-graduação em Psicologia (ANPEPP), como a organização de encontros, mesas-redondas e debates, durante 0 XI Simpósio de Pesquisa e Intercâmbio Científico (Florianópolis, 2006), a 60aㅡ e a $62^{\underline{a}}$ reuniões anuais da SBPC (Campinas, 2008 e Natal, 2010, respectivamente). Destes eventos resultaram iniciativas de ação e a divulgação de documentos que destacavam, entre outros itens, a necessidade da adotar

(...) instrumentos e procedimentos que sejam sensíveis/preservem a diversidade de concepções de ÉTICA, de PESQUISA e de CIÊNCIA que permeiam os modos de produção do conhecimento praticados em diferentes campos do conhecimento e respeitem a diversidade teórico-metodológica e temática que os caracterizam. (Associação Nacional de Pesquisa e Pós-graduação em Psicologia, 2012, s/p)
A mesma ANPEPP, em conjunto com a Associação Brasileira de Psicologia Social (ABRAPSO) e a Rede Nacional de Ensino e Pesquisa em Terapia Ocupacional (RENETO), elaborou e encaminhou ao Ministério da Saúde, em 2011, uma carta apontando a existência de inadequações no sistema e na atuação dos comitês. Nesta carta aquelas entidades denunciavam o

(...) caráter uniformizador e universalista da Res. CNS 196/1996. Uniformizador na medida em que (...) estabelece um modelo único de regulamentação de aspectos éticos na pesquisa com seres humanos; universalista na pretensão de que esse modelo único seja aplicável a toda e qualquer área de pesquisa com seres humanos. Embora pertinente e aplicável à pesquisa biomédica, o modelo de pesquisa em que se inspira a Res. 196 - e, por conseguinte, o modelo de regulamentação que prescreve ignora a diversidade epistemológica, teórico-metodológica e temática que caracteriza os diferentes campos de conhecimento em que se realizam pesquisas com seres humanos, manifestando-se particularmente insensível às especificidades dos processos de produção de conhecimento nas áreas das Ciências Humanas e Sociais. (Associação Nacional de Pesquisa e Pós-graduação em Psicologia, 2012, s/p, destaques no original).

Não obstante, todas as discussões efetivadas nestes diferentes encontros e documentos apoiavam e defendiam a existência de comitês de ética, mesmo que fossem organizados em outros moldes e atuassem sobre outras bases.

Sem que isto implique em uma defesa plena da Resolução 196/96 CNS, é preciso lembrar que esse documento já previa a necessidade de realizar "revisões periódicas (...), conforme necessidades nas áreas tecnocientífica e ética" (Conselho Nacional de Saúde, 2012, s/p.)

No período em que redijo este texto (setembro de 2012), o Conselho Nacional de Saúde está procedendo a uma revisão da Resolução. Para isto, organizou uma consulta pública através da qual foram encaminhadas 1.890 propostas de reformulação e mais alguns estudos detalhados sobre as inadequações daquela normativa (Conselho Nacional de 
Saúde, 2012). Não sabemos ainda o que vai resultar desta revisão. Não podemos garantir que as adequações atendam aos anseios e às necessidades de todos os grupos de pesquisadores. Tampouco sabemos se serão mantidos comitês unificados, responsáveis por todas as pesquisas envolvendo humanos, ou se, de imediato ou no futuro, teremos comitês específicos, por áreas, tal como foi aventado nas discussões promovidas pela ANPEPP.

O que podemos afirmar é que existem outras possibilidades de embasamento, direcionamento e atuação dos comitês, que vão além da manutenção da estrutura burocratizada atual, centrada na verificação do cumprimento de regras de conduta e baseada em concepções restritas e restritivas sobre a ética e a pesquisa científica, mas que também não implicam em deixar apenas por conta da boa vontade dos cientistas, individual e isoladamente, as discussões e preocupações com a ética.

Entre o controle burocrático atualmente em vigor e a política do laissez faire proposta por Ronie, felizmente há uma enorme gama de alternativas.

Pessoalmente continuo acalentando a concepção de que os comitês de ética em pesquisas que envolvam seres humanos ou não, unificados ou segmentados por áreas, deveriam constituir polos de discussão, aprofundamento e disseminação de reflexões sobre a Ética, sua complexidade e suas implicações, tanto para os pesquisadores quanto para os não cientistas. Além disso, os comitês teriam a responsabilidade de avaliar a coerência entre os procedimentos propostos nos projetos de pesquisa e intervenção e os princípios éticos adotados como básicos.

Aqui já teríamos uma diferença substancial em relação ao que ocorre atualmente: a meu ver, a atuação dos comitês deveria tomar como base conjuntos amplos de princípios, coletivamente elaborados e compartilhados, e não normativas restritas, como as contidas na parte final da Resolução 196/96 CNS. As formulações da bioética, sintetizadas no início da mesma resolução, ou o Código de Ética Profissional do Psicólogo (Conselho Federal de Psicologia, 2012), são exemplos do que denomino conjuntos amplos de princípios.

Assim acredito que, longe de tornar-se ainda mais trabalhosa, a tarefa de avaliação de projetos pelos comitês poderia tornar-se mais simples. Livres da tarefa de avaliação do cumprimento restrito de normas específicas e da verificação do preenchimento correto de documentos e formulários, os comitês poderiam concentrar-se naquilo que é (ou deveria ser) sua razão de existir: a preocupação com a ética.

Acredito que a grande maioria dos projetos não apresentaria divergências em relação aos princípios básicos. Para aqueles casos em que houvesse dúvidas ou discordâncias, o comitê deveria convocar o autor ou os responsáveis pelo projeto para debaterem suas proposições e defenderem a sua concepção sobre sua eticidade dessas proposições. Persistindo as discordâncias, a função do comitê não consistiria em impor um parecer unilateral, mas em ampliar o caráter público daquele debate.

Num exercício de reflexão, poderíamos imaginar uma situação limite, na qual a divergência entre as concepções dos proponentes de um projeto e as avaliações de um comitê persistissem, mesmo após a ampliação das discussões para outros fóruns mais amplos. Isto representaria uma dificuldade, sem dúvida; mas, por outro lado, teria o mérito de revelar a necessidade de que aquela divergência fosse debatida e superada de alguma forma.

Além disso, se adotarmos uma concepção dinâmica e participativa sobre a ética, devemos manter abertas duas possibilidades: uma, que os pareceres emitidos pelos comitês, favoráveis ou não à realização de um projeto de pesquisa, sempre possam ser contestados, em outras instâncias; e a outra, que o aprendizado derivado do estudo de casos específicos possa contribuir para a revisão dos princípios adotados anteriormente. $O$ papel dos comitês pode ou deve ser justamente 0 de realizar esta intermediação entre os princípios básicos assumidos e a realidade, tal como concebida e vivenciada pelos pesquisadores.

É consenso entre os cientistas que projetos de pesquisa devem conter, de forma clara e detalhada, além dos objetivos, os procedimentos previstos e as bases teóricas que os orientam. A exposição pública das intenções e dos aspectos teórico-metodológicos permite que estes itens sejam debatidos e criticados e que assim seja realizada a avaliação da qualidade do projeto como um todo.

Minha concepção é que as preocupações éticas devem merecer os mesmos cuidados e a mesma condição de obrigatoriedade que são exigidos para os aspectos teórico- 
metodológicos: devem ser claramente expressas para poderem tornar-se alvo de avaliações semelhantes.

Poderiam ser feitas pelos próprios cientistas, como propõe Silveira (2013)? Talvez; mas o fato é que, hoje, as exposições e discussões sobre a eticidade de um projeto de pesquisa não são um item tido como obrigatório nestes projetos, nem são habituais neles.

Além disso, vivemos um processo de acréscimo brutal da pressão por produtividade, entendida, infelizmente, como quantidade de produção. Diante desta pressão, parece inevitável que tudo aquilo que não for obrigatório seja ignorado.

Aqui entra, a meu ver, mais uma função para os Comitês: institucionalizar a inclusão daquelas discussões e reflexões sobre a ética nos projetos e relatórios de pesquisa, mas também no aprendizado, nas preocupações e no cotidiano dos cientistas, tal como ocorre com a teoria e a metodologia.

Por outro lado, concordo com as preocupações manifestadas por meu colega Silveira (2013), de que os comitês não podem servir como substitutos das reflexões éticas, nem são os únicos responsáveis por elas. Se os pesquisadores passarem a adotar concepções simplórias, confortáveis e equivocadas como as de que "meu projeto é ético porque foi aprovado pelo comitê" ou, mais genericamente, de que "ético é o que o Comitê diz que é", toda a riqueza potencial dos comitês terá sido perdida.

Aqui, mesmo discordando da forma como ele pretende atingir isto, concordo mais uma vez com Silveira (2013) quando afirma que as discussões éticas devem envolver um "(...) diálogo autêntico, aquele feito por agentes responsáveis (Silveira e Hünning, 2010) a partir dos pontos de vista que possuem e que não se envergonham de defender" (p. 175).

Continuemos, então, com nossos diálogos.

\section{REFERÊNCIAS}

Silveira, R. A. T., Hünning, S. (2010). Abib, J. A. D. (2008). Ensaio sobre desenvolvimento humano na pósmodernidade. Psicologia em Estudo, 13(3), 417-427

Associação Nacional de Pesquisa e Pós-graduação em Psicologia (2012). Relatório do Fórum de Ética em Pesquisa realizado no XIV Simpósio da ANPEPP - Belo Horizonte, junho de 2012. Recuperado em 31 de agosto de 2012, de http://www.anpepp.org.br/5-5Comissoes/Comis-etica/ComissaoXIVSimposio/ relatorio \%20comissao\%20etica\%20\% 20forum\%20final.pdf

Conselho Federal de Psicologia (2012). Código de Ética Profissional do Psicólogo - Resolução CFP no 002/87 de 15 de agosto de 1987. Recuperado em 3 de setembro de 2012 de http://www.crpsp.org.br/portal/orientacao/codigo/fr_codig o_etica_indice.aspx

Conselho Nacional de Saúde (2012). Revisão da Resolução CNS 196/96. Recuperado em 31 de agosto de 2012 de http://conselho.saude.gov.br/Web_comissoes/conep /index.html

Silveira, R. A. T. da (2013). Gambiarra Ética. Psicologia em Estudo, 18(1), 169-173.

Tomanik, E. A. (2008). A ética e os comitês de ética em pesquisa com seres humanos. Psicologia em Estudo, 13(2), 395-404.
Endereço para correspondência:
Eduardo Augusto Tomanik. Rua Kingston, 68, Jardim Canadá, CEP 87808090, Maringá-PR, Brasil.E-mail: eatomanik@gmail.com. 